\title{
MENJADI BIJAK BAGI PEMILIH PEMULA BERDASARKAN INFORMASI DARI MEDIA SOSIAL DI KABUPATEN KEPULAUAN MERANTI
}

\author{
Amir Syamsuadi'1), Seri Hartati'1), Diki Arisandi'2), Bahjatul Murtasidin' ${ }^{1}$, Luluk \\ Elvitaria $^{2)}$, Liza Trisnawati ${ }^{2}$ Yulia Febrianita ${ }^{3)}$ Putri Wulandini' ${ }^{3}$ \\ ${ }^{1)}$ Prodi Ilmu Pemerintahan, Fakultas Ilmu Sosial dan Politik, Universitas Abdurrab \\ 2) Prodi Teknik Informatika, Fakultas Teknik, Universitas Abdurrab \\ 3) Prodi Keperawatan, Fakultas Kedokteran dan Ilmu Kesehatan, Universitas Abdurrab \\ email: diki@univrab.ac.id
}

\begin{abstract}
ABSTRAK
Media sosial memiliki kelebihan lebih efektif sebagai sarana pertukaran ide, penyebaran berbagai ide, termasuk isi kampanye via media sosial secara cepat dan hampir tanpa batas. Media sosial juga bisa menjadi sarana untuk komunikasi di mana setiap individu saling memengaruhi, termasuk dalam hal mempengaruhi pemilih dan dalam hal ini adalah bakal pemilih pemula pada siswa sekolah menengah atas sederajat di Kabupaten Kepulauan Meranti. Pemilih pemula identik dengan smartphone dan juga media sosial. Mereka perlu diberi edukasi bagaimana menyikapi paradigma dan situasi berkaitan dengan pemilihan umum di media sosial. Kegiatan ini bertujuan untuk mengedukasi para pemilih pemula dalam menyikapi dan menentukan pilihan berdasarkan apa yang mereka lihat dimedia sosial, sehingga mereka memiliki pengetahuan yang cukup dan menjadi bijak untuk turut serta dalam kegiatan pemilihan umum.
\end{abstract}

Kata kunci: Pemilih Pemula, Media Sosial, siswa sekolah menengah atas, smartphone, pemilihan umum.

\begin{abstract}
Social media has more capabilities of transferring ideas, disseminating various purposes, including political campaign content through social media more quickly and almost without any boundaries. Social media can also as the communication tools where everyone influences each other, including in terms of influencing voters and in this case it will become a novice voter for high school students in the Meranti Islands Regency. Novice voters are identical to smartphones and social media. This activity aims to educate novice voters in determining and making choices based on what they experienced in social media so that they have sufficient knowledge and become wiser, and also ready to participate in the general election.
\end{abstract}

Key words: novice voters, social media, high school students, smartphone, general election. 


\section{PENDAHULUAN}

Kabupaten Kepulauan Meranti merupakan pemekaran dari Kabupaten Bengkalis yang dibentuk pada tanggal 19 Desember 2008 (Pemerintah Kabupaten Kepulauan Meranti, 2016). Secara aksesibilitas dan ketersediaan teknologi informasi, dapat dikatakan Kabupaten Kepulauan Meranti sudah tersentuh oleh teknologi informasi. Hal ini dapat dilihat dari ketersediaan akses jaringan berbasis $4 \mathrm{G}$ dan ketersediaan perangkat smartphone yang sudah dapat dirasakan penduduk di Kabupaten Kepulauan Meranti dari berbagai usia .

Berdasarkan data dari Biro Pusat Statistik Kabupaten Kepulauan Meranti, jumlah penduduk yang menempati usia sekolah menengah atas mencapai 17.258 jiwa (Badan Pusat Statistik Kabupaten Kepulauan Meranti, 2016). Usia anak sekolah menengah atas umumnya berkisar antara enam belas hingga delapan belas tahun, bila dilihat dari kecukupan usia dalam pemilu, maka rentang usia tersebut sudah memiliki hak memilih dan dikategorikan sebagai pemilih pemula.

Pemilih pemula pada umumnya belum memiliki pengalaman dan pengetahuan seputar pemilihan umum. Sebagai generasi yang tumbuh pada era milenial, selalu menggunakan smartphone, dan aktif dimedia sosial, mereka kerap mendapatkan porsi informasi lebih banyak di media sosial. Dari sisi kurang mampunya mereka dalam memilah informasi yang banyak beredar di media sosial dan kurangnya pengalaman dalam melakukan literasi akan menyebabkan pemilih pemula ini menjadi pihak yang mudah terbawa arus informasi, dan dikhawatirkan akan menyebabkan mereka berpotensi menjadi swing voters atau terjebak dalam informasi-informasi yang bersifat hoax

\section{TINJAUAN PUSTAKA}

\section{Media sosial}

Media sosial merupakan sebuah media berbasis online, dengan para penggunanya bisa dengan mudah berpartisipasi, berbagi, dan menciptakan konten (Priambada, 2015). Saat teknologi internet dan mobile phone makin maju maka media sosial pun ikut tumbuh dengan pesat. Kini untuk mengakses media sosial, bisa dilakukan dimana saja dan kapan saja hanya dengan menggunakan smartphone, perangkat komputer, ataupun keduanya (Fitri, 2017) seperti yang terlihat digambar 1 .

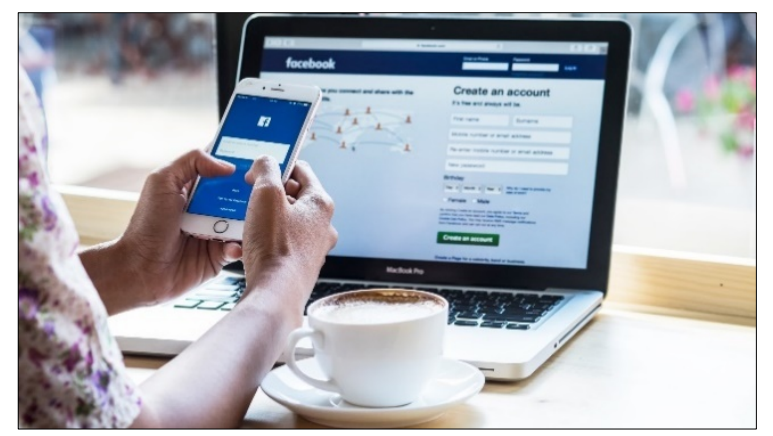

Gambar 1. Pengguna Mengakses Media Sosial Pada Perangkat Yang Berbeda

Demikian cepatnya orang bisa mengakses media sosial mengakibatkan terjadinya fenomena besar terhadap arus informasi tidak hanya di negara-negara maju, tetapi juga di Indonesia. Karena kecepatannya media sosial juga mulai tampak menggantikan peranan media massa konvensional dalam menyebarkan berita-berita. 
Selain berpengaruh terhadap penyebaran berita, media sosial juga banyak digunakan dalam mempromosikan sesuatu (Sukri \& Arisandi, 2017b). Sebagai contoh pada saat ini sudah lazim jika orang sudah mempromosikan produk kuliner dengan menggunakan media sosial (Arisandi \& Sukri, 2017), salah satu alasannya adalah penyebaran dan pembaharuan informasi melalui media sosial lebih cepat dibandingkan media konvensional (Sukri \& Arisandi, 2017a).

2. Pemilihan umum

Pemilihan umum yang disingkat menjadi pemilu diselenggarakan tidak lain adalah masalah politik yang berkaitan dengan pergantian pemimpin. Dalam sebuah negara demokrasi, pemilu merupakan salah satu pilar utama dari sebuah proses penyaluran aspirasi masyarakat (Saputra \& Asih, 2017). Pemilihan umum dianggap merupakan tahap awal dari berbagai rangkaian kehidupan tatanegara yang demokratis, sehingga pemilu merupakan penggerak mekanisme sistem politik berdemokrasi, terutama di Indonesia (Akbar, 2016).

Pemilihan umum merupakan suatu keharusan bagi suatu negara yang menamakan dirinya sebagai negara demokrasi. Sampai sekarang pemilihan umum masih dianggap sebagai suatu peristiwa ketatanegaraan yang penting, karena pemilu melibatkan rakyat secara keseluruhan yang memenuhi syarat-syarat (Sardini, 2011). Berdasakan peraturan yang ditetapkan oleh Komisi Pemilihan Umum (KPU) ada tiga syarat yang wajib bagi warga negara untuk tercatat sebagai pemilih, yaitu merupakan Warga Negara Indonesia (WNI), berusia 17 tahun atau lebih saat memilih, pernah atau pun sudah menikah (Surbakti, Supriyanto, \& Santoso, 2011).

3. Pemilih pemula

Pemilih Pemula adalah Warga Indonesia yang pada hari pemilihan atau pemungutan suara adalah Warga Negara Indonesia yang sudah genap berusia 17 tahun dan atau lebih atau sudah / pernah kawin yang mempunyai hak pilih, dan sebelumnya belum termasuk pemilih karena ketentuan Undang-Undang Pemilu. Pemilih pemula di Indonesia kebanyakan masih Pelajar dari tingkat sekolah menengah atas dan Mahasiswa, sehingga permasalahan yang berhubungan dengan pemula perlu dipandang lebih penting. Karena mereka yang dianggap paling riskan terhadap pengaruh - pengaruh negatif, seperti dari media sosial, sehingga dalam pemilu mereka memerlukan pendekatan yang lebih nyata melalui program-program dari pihak yang terkait (Batawi, 2013).

\section{Swing voters}

Swing voters adalah perilaku pemilih yang berubah atau berpindah pilihan partai atau calon dari satu Pemilu ke Pemilu berikutnya. Secara keanggotaan, biasanya swing voters tidak berafiliasi dengan partai tertentu. Pada beberapa event pemilu, partai politik juga memberi perhatian kepada para swing voters agar memberikan dukungannya. Hal-hal yang lazim dijumpai dari swing voters yaitu dilihat dari faktor usia, biasanya swing voters termasuk golongan pemilih pemula yang berusia muda 
sehingga mudah untuk dipengaruhi. Adapun hal lainnya yaitu lazim dijumpai bahwa swing voters adalah orang-orang yang menginginkan perubahan atau memiliki kekecewaan terhadap partai sebelumnya (Mohamed, 2013).

\section{Hoax}

Hoax adalah sebagai rangkaian informasi yang memang sengaja disesatkan, namun bisa disamarkan sebagai kebenaran. Hoax merupakan berita palsu yang mengandung informasi yang sengaja menyesatkan orang dan memiliki agenda tertentu. Hoax bukan sekedar misleading alias menyesatkan, informasi dalam fake news juga tidak memiliki landasan faktual, namun disajikan seolah-olah sebagai serangkaian fakta (salam). Saat ini hoax apalagi terkait dengan aktivitas politik sering muncul di internet, terutama di media sosial dan memiliki tujuan tertentu, misalnya ketidakpercayaan, ketakutan, kepanikan dan lain sebagainya (Legionosuko \& Harnowo, 2017).

\section{METODE PELAKSANAAN}

Dalam melakukan Pengabdian Kepada Masyarakat di Kabupaten Kepulauan Meranti, Pengabdi melakukan beberapa langkah-langkah kegiatan seperti pada gambar berikut:

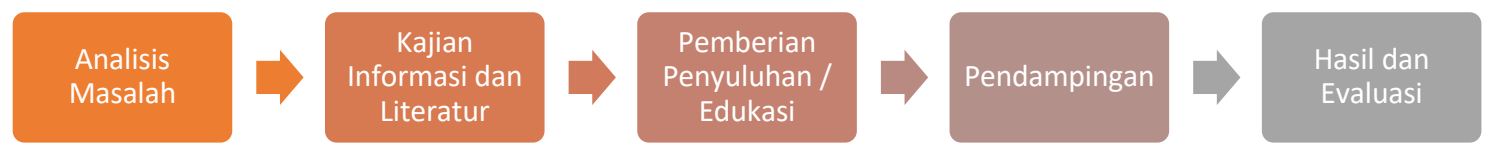

Gambar 2. Tahapan Kegiatan

Kegiatan ini bermula dari hasil diskusi dengan beberapa guru dan kepada sekolah tentang permasalahan pada remaja sekolah menengah atas di Kabupaten Kepulauan Meranti, yaitu tentang kurangnya pengetahuan mereka sebagai pemilih pemula yang akan berpartisipasi dalam pemilu. Selain itu, tidak bisa dipungkiri bahwa usia remaja sekolah menengah ini sangat akrab dengan smartphone, namun penggunaannya tidak meliterasi hal-hal yang berkaitan dengan pemilihan umum.

Sebelum melaksanakan penyuluhan, perlu kiranya mendalami informasi dan literatur yang terkait dengan pemilih pemula seperti payung hukum pemilu, mekanisme dalam memilih bagi pemilih pemula, dan hal-hal lainnya. Selain hal-hal yang berkaitan dengan pemilu, tim juga harus menyiapkan informasi-informasi tentang ketersediaan layanan internet dilokasi pengabdian, perilaku objek pengabdian dalam mengakses informasi melalui internet, serta cara yang bisa dilakukan dalam melakukan penyaringan informasi di media sosial.

Kegiatan penyuluhan ini diadakan disekolah-sekolah menengah atas di Kabupaten Kepulauan Meranti. Namun dikarenakan letak geografis dan ketersediaan waktu, maka kegiatan dipusatkan didaerah Tebingtinggi. Hal ini dikarenakan sekolah atas yang ada di Kabupaten kepulauan Meranti sebagian besar berada didaerah Tebingtinggi. Selain itu, ketersediaan layanan internet pada daerah ini sudah memadai (berwarna hijau dan dilingkari hitam) seperti yang terlihat pada gambar 3 . 


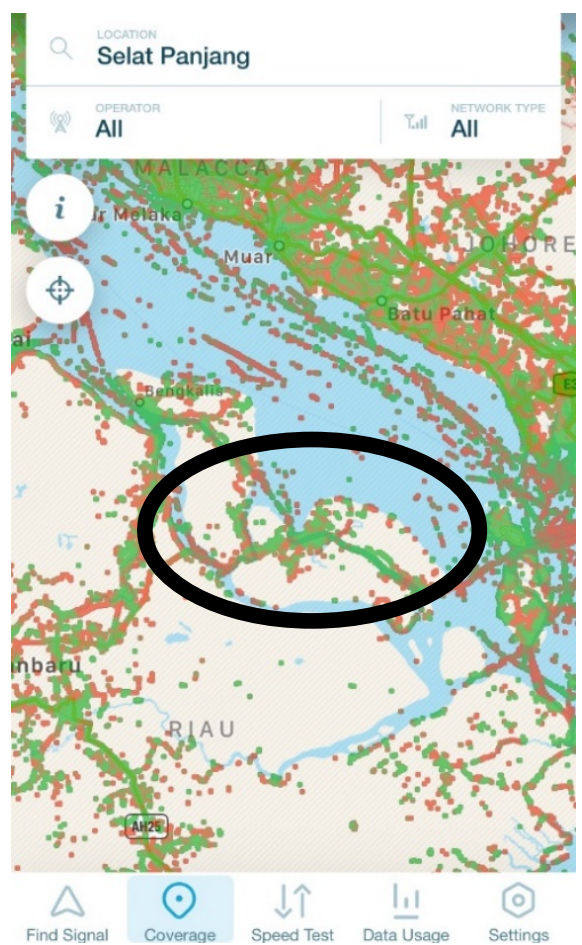

Gambar 3. Cakupan Ketersediaan Layanan Internet di Meranti.

Kegiatan penyuluhan akan berbentuk talk show dan diskusi terkait dengan pemanfaatan media sosial bagi pemilih pemula, lalu kegiatan akan dilanjutkan dengan diskusi agar para peserta dapat menanyakan hal-hal yang belum dipahami. Setelah kegiatan penyuluhan atau edukasi selesai dilakukan, tim pengabdi tetap membuka diri untuk konsultasi, diskusi atau tanya jawab secara personal terkait dengan pemanfaatan media sosial bagi para remaja yang berstatus pemilih pemula melalui media sosial seperti Whatsapp. Hal ini dilakukan agar mereka menjadi semakin paham dan siap dalam menghadapi pemilihan umum berbekal dengan informasi-informasi yang sudah mereka dapatkan.

Hasil dari kegiatan ini akan didiskusikan dalam internal tim dan juga diinformasikan kepada pihak sekolah mengenai ketercapaian program ini. Selain itu, hasil kegiatan ini juga bisa menjadi evaluasi bagi tim pengabdi agar kedepannya dapat melakukan kegiatan pengabdian yang lebih baik lagi.

\section{HASIL DAN PEMBAHASAN}

Kegiatan pengabdian difokuskan didaerah kecamatan Tebingtinggi, hal ini didasari dari data yang didapat dari Dapodikdasmen dan data ketersediaan akses internet untuk daerah Meranti dari aplikasi speedtest. Berdasarkan data dari dapodik, jumlah sekolah menengah atas sederajat didaerah kecamatan Tebingtinggi berjumlah 14 sekolah, separuh dari seluruh jumlah sekolah menengah atas sederajat di kabupaten kepulauan Meranti. Begitu juga dengan kesediaan akses internet, Tebingtinggi memiliki ketersediaan akses internet yang lebih baik daripada daerah yang lain.

Sebelum melakukan edukasi dan penyuluhan kepada para siswa, tim pengabdi melakukan kegiatan diskusi dengan para guru seperti yang terlihat pada gambar 4.1. 


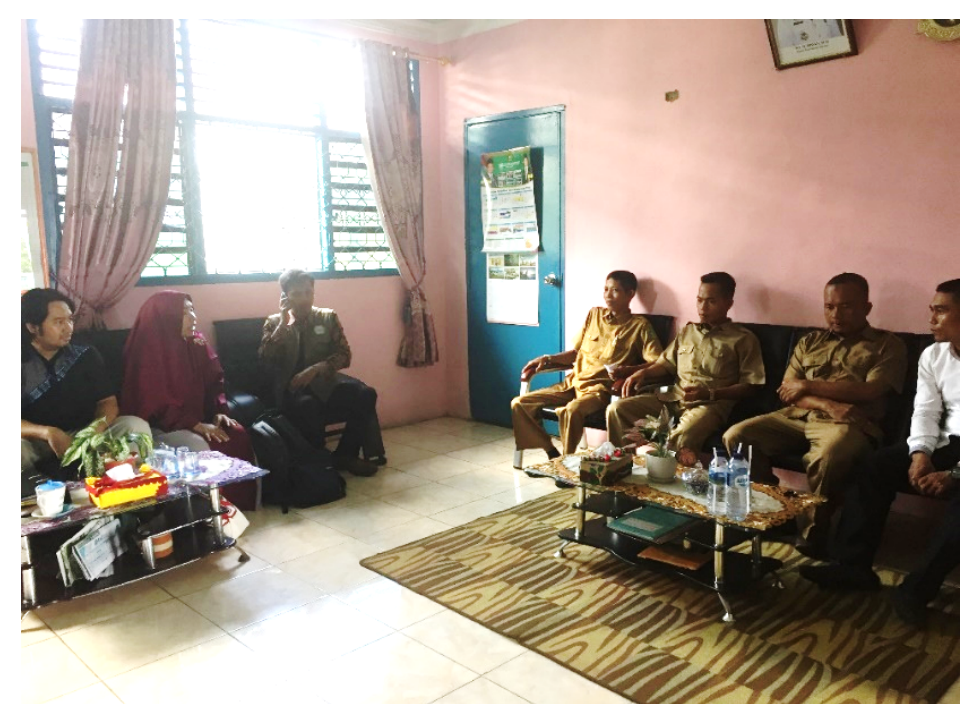

Gambar 4. Diskusi Dengan Para Guru

Kegiatan diskusi pada gambar 4 bertujuan untuk mengetahui perilaku atau kebiasaan yang sering dilakukan oleh para siswa dalam menggunakan smartphone. Hal yang didapat dari kegiatan diskusi dan dengar pendapat dengan ara guru yaitu bahwa siswa lebih banyak menggunakan smartphone nya untuk mengakses media sosial.

Sama halnya dengan pendapat para guru, survey dari APJII (Asosiasi Penyelenggara Jasa Internet Indonesia) yang dirilis pada tahun 2017 (APJII, 2017) menyatakan hal yang serupa. Hasil survey berdasarkan pengguna usia menunjukkan bahwa rentang usia sekolah menengah menunjukkan angka pengguna tertinggi. Hasil ini dapat dilihat pada gambar 5 .

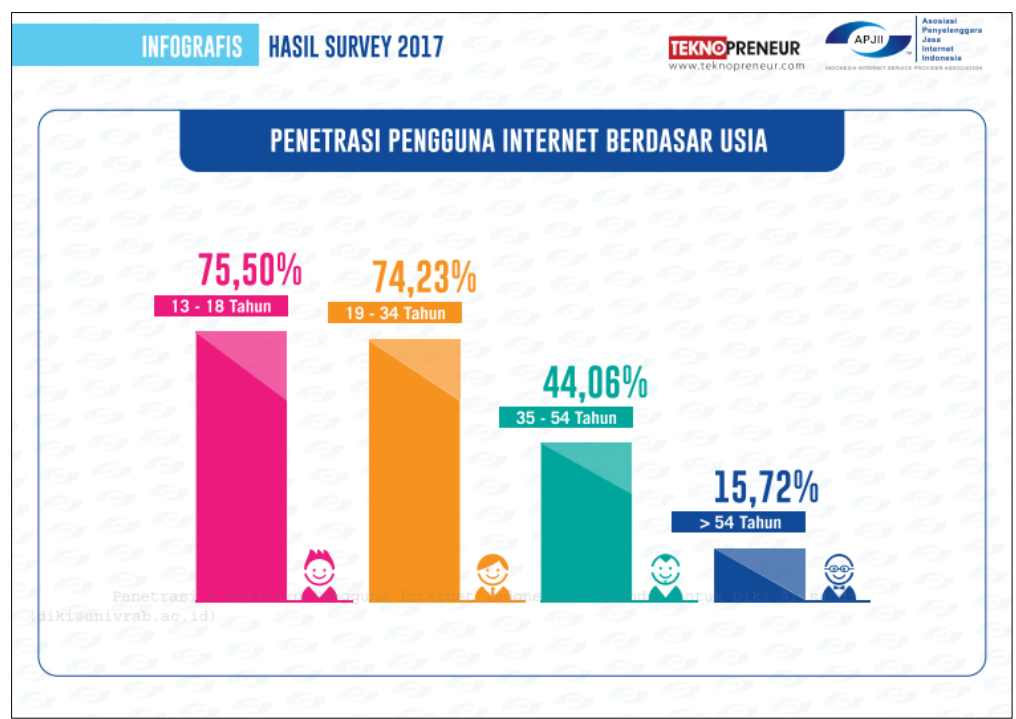

Gambar 5. Pengguna berdasarkan Usia

Hal yang berkaitan juga ditunjukkan hasil survey yang serupa, dimana penggunaan internet didominasi oleh konten media sosial seperti chatting dan situs pertemanan. Hal ini dapat dilihat pada gambar 6 berikut. 


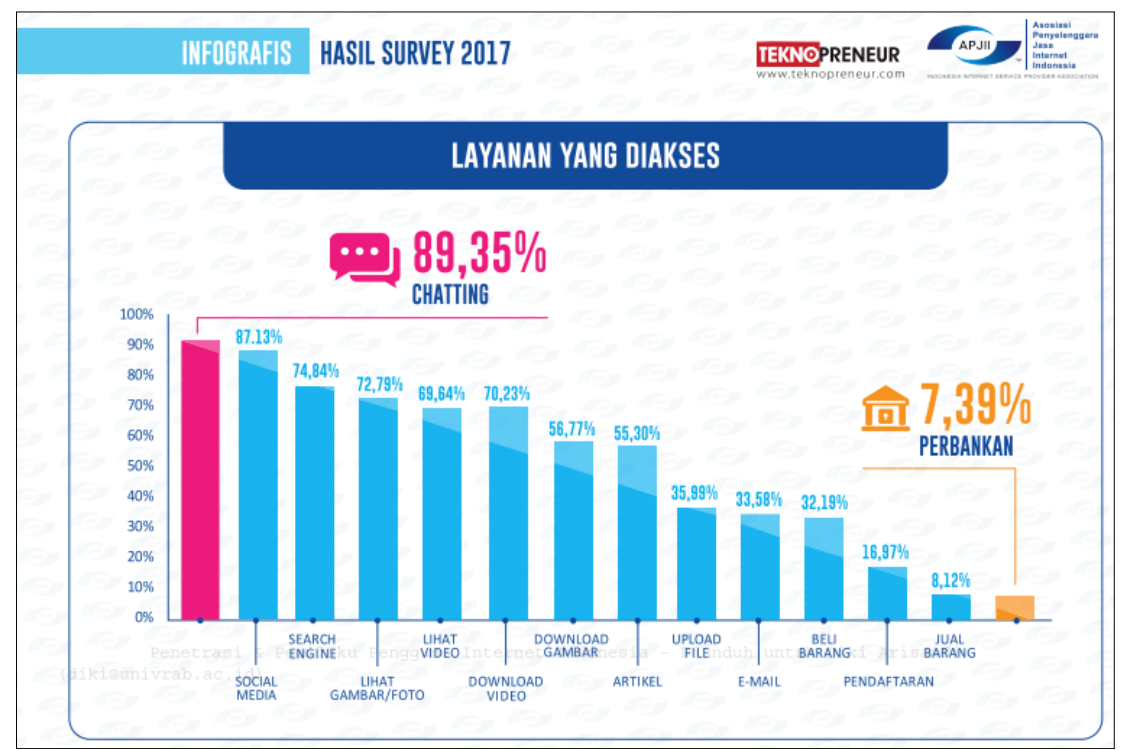

Gambar 6. Pengguna berdasarkan Layanan Yang Diakses

Atas uraian dan gambar yang telah dijelaskan sebelumnya, bisa disimpulkan bahwa remaja usia sekolah menengah atas akan banyak meliterasi informasi yang mereka dapatkan dari media sosial. Kegiatan pengabdian ini berupa penyuluhan atau edukasi kepada para siswa tentang bagaimana memanfaatkan media sosial sebagai alternatif referensi sebagai pemilih pemula kebeberapa sekolah. Kegiatan dimulai dengan penjelasan dari tim pengabdi tentang pemilihan umum dan teknis tatacaranya. Penyuluhan dilanjutkan dengan informasi-informasi apa saja yang dapat dimanfaatkan dari media sosial terkait status mereka sebagai pemilih pemula, dan tentunya membekali mereka dengan bagaimana cara yang dapat dilakukan untuk menepis informasi yang sifatnya hoax atau terkait dengan black campaign di media sosial, seperti yang terlihat pada gambar 7 .

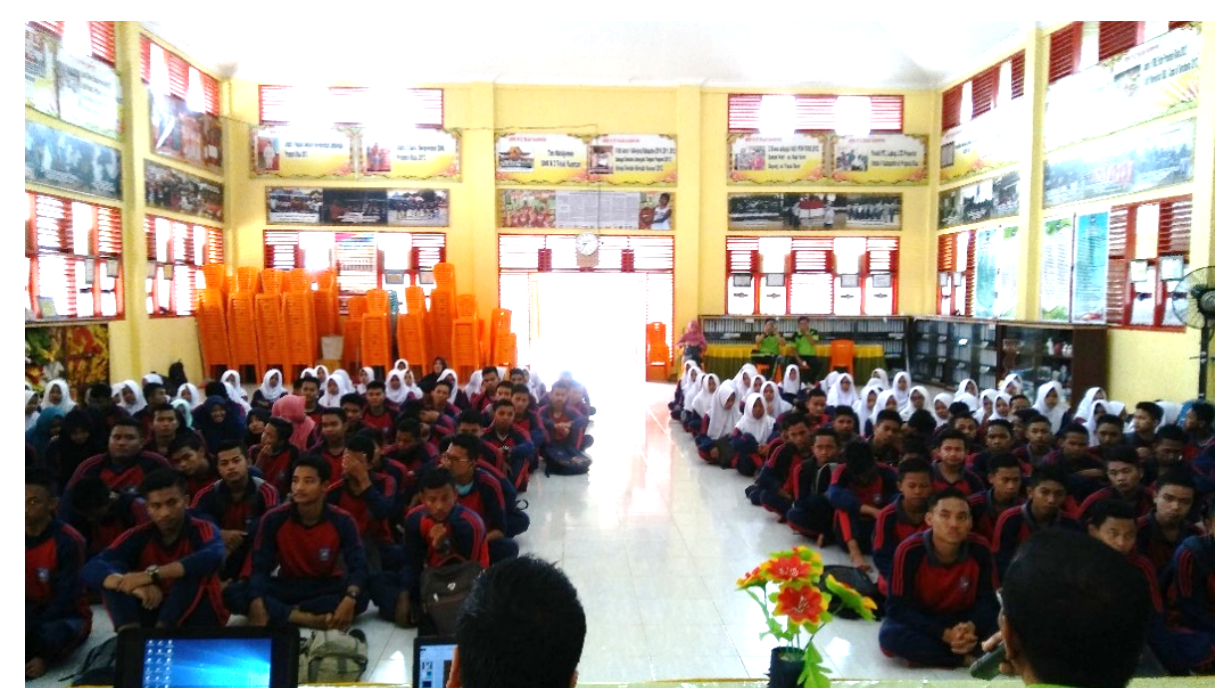

Gambar 7. Siswa Sedang Menyimak Materi Dari Tim Penyaji

Pada beberapa tempat yang dikunjungi tim pengabdi, adakalanya mereka meminta kegiatan berupa diskusi per kelompok kecil setelah dilakukan pemaparan dari tim pengabdi. Tentunya hal ini disambut baik oleh tim, karena hal in idapat menambah 
pengetahuan mereka seputar hal-hal yang berkaitan dengan pemanfaatan media sosial dalam mencari informasi terkait pemilihan umum bagi mereka yang berstatus sebagai pemilih pemula. Kegiatan diakhiri dengan foto bersama seperti pada gambar 8 .

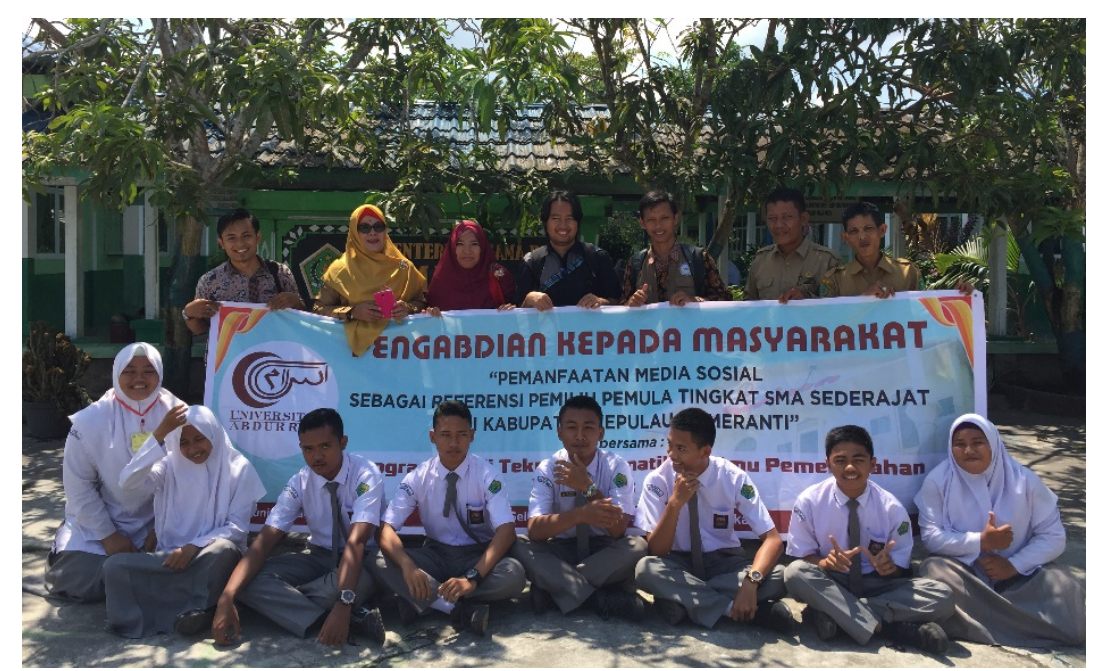

Gambar 8. Foto Bersama Setelah Sesi Diskusi

\section{KESIMPULAN}

Setelah kegiatan selesai dilakukan, maka dapat disimpulkan bahwa para pemilih pemula khususnya yang ada di Kabupaten Kepulauan Meranti memerlukan edukasi guna mempersiapkan mereka menjadi peserta pemilihan umum. Referensi yang didapat dari media sosial memang tidak semuanya benar, namun perlu adanya filter atau cara bagaimana memilah dan memilih informasi terkait pemilihan umum maupun kegiatan kampanye. Hal ini bertujuan agar para pemillih pemula ini bisa menjadi bijak dalam memanfaatkan media sosial, tidak terjebak dalam black campaign, ataupun menjadi swing voters. Untuk selanjutnya agar kegiatan ini dapat dilaksanakan secara berkesinambungan dan kontinyu dalam rangka menghasilkan para pemilih yang nantinya akan menentukan nasib bangsa.

Tim pengabdi mengucapkan terimakasih kepada LPPM Universitas Abdurrab yang sudah membantu dari segi pembiayaan dan administrasi, dan juga pihak sekolah yang tim pengabdi kunjungi yang sudah meluangkan waktunya agar kegiatan ini terlaksana.

\section{DAFTAR PUSTAKA}

[5]. Akbar, I. (2016). Demokrasi Dan Gerakan Sosial (Bagaimana Gerakan Mahasiswa Terhadap Dinamika Perubahan Sosial). Jurnal Wacana Politik, 1(2). https://doi.org/10.24198/jwp.v1i2.11052

[6]. APJII. (2017). Penetrasi \& Perilaku Pengguna Internet Indonesia 2017. Asosiasi Penyelenggara Jasa Internet Indonesia.

[7]. Arisandi, D., \& Sukri, S. (2017). An Analysis of the Expediency Social Media for Culinary Products Marketing on Micro and Middle Enterprise in Pekanbaru City. IOP Conference Series: Earth and Environmental Science, 97(1). https://doi.org/10.1088/1755-1315/97/1/012002 
[8]. Badan Pusat Statistik Kabupaten Kepulauan Meranti. (2016). Kepulauan Meranti Regency in Figures 2016 (1102001.1410 No. 1410.2016.01). Selat Panjang.

[9]. Batawi, J. W. (2013). Tingkat Kesadaran Politik Pemilih Pemula dalam Pilkada Suatu. UNIERA, 2(Vii), 216-231.

[10]. Fitri, S. (2017). Dampak Positif Dan Negatif Sosial Media Terhadap Perubahan Sosial Anak. Naturalistic: Jurnal Kajian Penelitian Pendidikan Dan Pembelajaran 1, 2, 118-123.

[11]. Legionosuko, T., \& Harnowo, S. (2017). Dinamika fake news atau hoax sebagai sumber konflik horisontal pada pilkada propinsi dki tahun 2017 dynamics fake news or hoax as a source of horizontal conflict in the provincial poverty of dki jakarta 2017. Jurnal Prodi Damai Dan Resolusi Konflik, 3(3), 111-136.

[12]. Mohamed, N. S. P. (2013). CHAMPIONING POLITICAL CAMPAIGNING TOWARDS FIRST-TIME VOTERS. Jurnal Komunikasi: Malaysian Journal of Communication, 29(2), 79-86. Retrieved from http://0search.ebscohost.com.wam.city.ac.uk/login.aspx?direct=true $\& d b=$ psyh $\& A N=20$ 09-99090-425\&site=ehost-live

[13]. Pemerintah Kabupaten Kepulauan Meranti. (2016). Naskah Akademik Kabupaten Meranti.

[14]. Priambada, S. (2015). Manfaat penggunaan media sosial pada usaha kecil menengah (UKM). SESINDO 2015, 2015.

[15]. Saputra, I., \& Asih, N. W. (2017). Kepemimpinan perempuan dan pilkada serentak. Aristo, 5(1), 141-162. https://doi.org/10.24269/ARS.V5I1.424

[16]. Sardini, N. H. (2011). Restorasi penyelenggaraan pemilu di Indonesia. Fajar Media Press.

[17]. Sukri, S., \& Arisandi, D. (2017a). Analisa Pembeli Kuliner Terhadap Pembaharuan Informasi Melalui Media Sosial Di Kota Pekanbaru. Jurnal RESTI (Rekayasa Sistem Dan Teknologi Informasi), 1(2), 122-130. https://doi.org/https://doi.org/10.29207/resti.v1i2.42

[18]. Sukri, S., \& Arisandi, D. (2017b). Analisis Strategi Pemasaran Dengan Media Sosial Produk Kuliner Usaha Kecil dan Menengah di Pekanbaru. Jurnal Buana Informatika, 8(4), 235-242. https://doi.org/https://doi.org/10.24002/jbi.v8i4.1447

[19]. Surbakti, R., Supriyanto, D., \& Santoso, T. (2011). Penanganan pelanggaran pemilu. Kemitraan bagi Pembaruan Tata Pemerintahan. 